\title{
Chemical Characterization, Antimicrobial, Antiproliferative and Antioxidant Activities of the Essential Oil of Monarda citriodora Growing in Kashmir
}

\author{
Abdul Rouf Wani*, Kanchan Yadav \\ Department of Botany, Madhyanchal Professional University, Bhopal, Madhya Pradesh, INDIA.
}

\begin{abstract}
Objectives: The main aim of this research was to evaluate phytochemicals, antimicrobial, antiproliferative and antioxidant Activities of the essential Oil of Monarda citriodora growing in Kashmir (India). Materials and Methods: Essential oil obtained by hydrodistillation from the flowers of Monarda citriodora was analysed by a combination of capillary gas chromatographymass spectrometry (GC-MS) and gas chromatography-flame ionization detector (GC-FID) techniques. The essential oil was evaluated for its antimicrobial and antioxidant potential. Antimicrobial activity was evaluated against two fungal and seven bacterial strains. The antiproliferative efficacy was evaluated by Sulphorhodamine-B assay. Results: A total of 13 components were identified constituting $99.4 \%$ of the total oil composition. Thymol (79.7\%), P-cymene (7.7\%), Tricyclene $(4.5 \%)$ and carvacrol $(3.0 \%)$ were found to be the major components. The oil composition was totally dominated by oxygenated monoterpenes constituting $83.2 \%$. Additionally, potent and broad-spectrum of antimicrobial activities were shown by the essential oil. In vitro cytotoxic studies revealed concentration dependent growth inhibition of all target cancer cell lines in the $10-100 \mu \mathrm{g} / \mathrm{ml}$ dilution range, with $I_{50}$ values of $24.2 \mu \mathrm{g} / \mathrm{ml}$ (THP-1), $55.5 \mu \mathrm{g} / \mathrm{ml}$ (A-549), $31 \mu \mathrm{g} / \mathrm{ml}$ (HEP-2) and $37.5 \mu \mathrm{g} / \mathrm{ml}$ (Caco-2). Antioxidant studies of the essential oil
\end{abstract}

evaluated by two complementary assays viz DPPH and hydroxyl radical assays confirmed that the oil exhibited potent and dose-dependent inhibition of the DPPH and hydroxyl radicals with $I C_{50}$ values of $19.3 \mu \mathrm{g} / \mathrm{ml}$ and $39.2 \mu \mathrm{g} / \mathrm{ml}$ respectively. Conclusion: We concluded that the essential of Monarda citriodora growing in Kashmir is rich in chemical composition and possess significant antimicrobial, antioxidant and antiproliferative activities.

Key words: Monarda citriodora, GC-MS, Antibacterial activity, antiproliferative activity, Essential oil

\section{Correspondence}

Mr. Abdul Rouf Wani,

Department of Botany, Madhyanchal Professional University, Bhopal-462044, Madhya Pradesh, INDIA.

Email id: roufwani998@gmail.com;

ORCID: https://orcid.org/0000-0002-0758-8228

DOI: 10.5530/ijpi.2021.2.31

\section{INTRODUCTION}

In addition to being ineffective in many cases due to emergence of resistant microbial strains, Present antibiotic therapies are frequently accompanied by a large number of toxic side effects, ${ }^{1}$ These resistant strains such as methicillin-resistant $S$. aureus (MRSA), Vancomycinresistant Enterococci (VRE) and multi drug-resistant strains of $K$. pneumonia and $P$. aeruginosa give birth to nosocomial infections which are characterized by high morbidity and mortality rates and hence pose a serious problem worldwide. ${ }^{2-4}$ Novel and sustainable antimicrobials are crucial in solving this problem. Plant extracts and essential oils, which represent natural complex multi-component systems composed mainly of terpenes in addition to some other non-terpene components, have always had choice of use for different purposes. ${ }^{5,6}$ Plant essential oils have been screened for their antimicrobial, carminative, antioxidant, spasmolytic, antiviral, hepato-protective, and anticancer properties. ${ }^{7-11}$ A great concern in studying antimicrobial properties of essential oils is emergence of antibiotic resistance. These detailed investigations culminated into results depicting significant antibacterial activity of many plant essential oils against a range of resistant microbial strains. ${ }^{12-14}$ This special property of essential oils, being effectively active in resistant strains is governed by their diverse chemical profile which as a tool empowers essential oils to be multi target oriented in their action against various infections.

In addition to being anti-microbial and antioxidant in nature, some essential oils along with their constituents have been reported to exert both in-vitro and in-vivo anti-tumour activity against human breast adenocarcinoma cell lines, colon neuroblastoma, lung cancer cell lines, oral carcinoma (KB) murine leukemia (P388) and melanoma cells. ${ }^{15-19}$ Further, the chemotherapeutic values of some essential oil components against cancer cells have been under scrutiny in Phase I clinical trials which authenticate their anti-tumour activity. ${ }^{20}$

Monarch citriodora var. citriodora, which is native to North America and naturalized in Europe, is an annual herbaceous plant. Common names of this plant include purple horsemint, lemon mint, and lemon bee balm. ${ }^{21}$ Plants of Monarda species have been used as garden plants, flavoring and food additives and for medicinal purposes. Oils isolated from plants of the same species grown in diverse geographical areas may be very different. Reminiscent odor of lemons is evolved on crushing its leaves.

Reviewing the potential ethanomedicinal promises of this plant, we have undertaken a research programme to investigate not only volatile chemical composition of essential oil but also screen it for various biological activities like those of antimicrobial, antioxidant and cytotoxicity which as per literature survey constitutes the first documentary report on this plant.

\section{MATERIALS AND METHODS}

\section{Chemicals}

DPPH (2,2-dipheny-1-picryl hydrazyl), dry ferric chloride, dimethyl sulfoxide, L- ascorbic acid and methanol, were procured from Sigma (St. Louis, MO). All the chemicals/solvents used were analytical grade. 


\section{Plant material and Essential oil extraction}

The aerial part of Monarda citriodora was collected from Gulmarg (Kashmir) during July-2019. Five kilograms of the fresh plant material in six installments was subjected to hydrodistillation using a Clevenger type apparatus for $3 \mathrm{hr}$ according to the procedure described in the European Pharmacopoeia. To eliminate the moisture essential oil was treated with anhydrous sodium sulphate and then stored at $4^{\circ} \mathrm{C}$. Calculation of the yield was performed on fresh weight basis and was found to be $0.50 \%(\mathrm{~V} / \mathrm{W})$.

\section{Gas Chromatography/Flame Ionization Detector and Gas Chromatography Mass Spectrometry analysis}

GC/FID was carried out on Perkin Elmer auto system XL Gas Chromatograph 8500 series equipped with flame ionization detector (FID) and head space analyzer using a fused silica capillary RTX-5 column $(30 \mathrm{~m} \times 0.32 \mathrm{~mm}$, film thickness $0.25 \mu \mathrm{m})$ coated with dimethyl polysiloxane. Oven temperature was programmed from $60^{\circ} \mathrm{C}$ to $280^{\circ} \mathrm{C}$ and varied at a rate of $3^{\circ} \mathrm{C} / \mathrm{min}$. Injector temperature was maintained at $230^{\circ} \mathrm{C}$ and detector temperature $250^{\circ} \mathrm{C}$. Injection volume of $1 \mu \mathrm{l}$ was used and nitrogen was used as a carrier gas with flow rate of $1.0 \mathrm{~mL} / \mathrm{min}$. GC-MS analysis was carried on a Varian Gas Chromatograph series 3800 fitted with a VF- $5 \mathrm{~ms}$ fused silica capillary column $(60 \mathrm{~m} \times 0.25 \mathrm{~mm}$, film thickness $0.25 \mu \mathrm{m}$ ) coupled with a 4000 series mass detector under the following conditions: injection volume $0.5 \mu \mathrm{l}$ with split ratio 1:60, helium as carrier gas at $1.0 \mathrm{~mL} / \mathrm{min}$ constant flow rate, injector temperature $230^{\circ} \mathrm{C}$ oven temperature $60^{\circ} \mathrm{C} / \mathrm{min}$. Mass spectra: electron impact (EI+) mode, $70 \mathrm{ev}$ and ion source temperature $250^{\circ} \mathrm{C}$. The a.m.u range of 50-500 a.m.u was set to record the mass spectra.

Identification of various constituents was done on the basis of Retention Index (RI), co-injection with standards (Sigma Aldrich and standard isolates), MS Library search (NIST 05 and WILEY), by comparing with the MS literature data. ${ }^{22,23}$ The individual components relative percentages were measured without using correction factors based on GC peak area (FID response).

\section{Microbial Strains, Antimicrobial Activity Assay and Minimum Inhibitory Concentrations}

The antimicrobial activity of essential oil of Monarda citriodora was tested against seven aerobic, Gram positive and Gram negative bacterial strains and two fungal strains which account for the major group of pathogens. The bacterial and fungal strains against which activity was assessed included Bacillus subtilis MTCC-441, Staphylococcus epidermidis MTCC-435, Pseudomonas aeruginosa MTCC-1688, Staphylococcus aureus MTCC 96, Salmonella typhi MTCC-531, Shigella dyssenteriae MTCC-369, Klebsiella pneumonia MTCC-19, Penicillium chrysogenum MTCC 947 and Aspergillus niger MTCC 1344 and were obtained from Microbial Type Culture Collection (MTCC), Institute of Microbial Technology (IMTECH) Chandigarh, India. All the bacterial strains were sub-cultured on Muller-Hinton agar (Himedia) slants every fifteen days to maintain the bacterial viability. Test conditions were in full agreement with CLSI Protocol M7A6 requirements.

Antibacterial activity of essential oil of Monarda citriodora was determined by agar well diffusion method. Bacterial strains were grown overnight at $37^{\circ} \mathrm{C}$ in Mueller-Hinton Broth (Himedia). $100 \mu$ l of standardized inoculum ( $0.5 \mathrm{Mac}$-Farland) of each strain was inoculated on molten Muller-Hinton agar, homogenized and poured into sterile $90 \mathrm{~mm}$ petri dishes and were allowed to solidify under laminar air flow. Standard cork borer of $5 \mathrm{~mm}$ diameter was used to make wells, into which $50 \mu \mathrm{l}$ essential oil dissolved in DMSO was added. Vancomycin and Ampicillin (10 $\mu \mathrm{g} / \mathrm{disc})$ were used as positive control and DMSO alone as negative control.
A laboratory film was used to cover each petri dish to evade evaporation followed by incubation at $37 \pm 1^{\circ} \mathrm{C}$ for $24 \mathrm{hr}$. Finally, a standard scale was used to mark the inhibition zone to the nearest size. ${ }^{24}$ Each experiment was replicated in triplicates and data was revealed as mean \pm SD.

Minimum inhibitory concentrations were obtained using broth dilution method. ${ }^{25}$ Desired concentrations $(0.125-625 \mu \mathrm{g} / \mathrm{ml})$ were generated by diluting each sample in sequence with Muller Hinton broth. Bacterial strains were adjusted to $0.5 \mathrm{McF}$ arland standard turbidity. Each sample was stirred and inoculated with $50 \mu \mathrm{l}$ of tested bacterial suspension containing $2 \times 10^{5} \mathrm{CFU} / \mathrm{ml}$ and incubated at $37 \pm 1^{\circ} \mathrm{C}$ for $24 \mathrm{hr}$. The lowest concentration at which no evident growth was seen post incubation in test bacteria was considered as MIC value.

\section{Antioxidant activity by Free radical-scavenging and Hydroxyl radical scavenging methods}

Antioxidant properties of Monarda citriodora essential oil were evaluated as both free radical scavenging capacity (RSC) and protective effect on the lipid peroxidation (LP). Free radical scavenging activity of the oil was assessed by evaluating the scavenging potency (Table 1) on 1-diphenyl2-picryl hydrazyl radical (DPPH) ${ }^{12}$ A $0.5 \mathrm{mM}$ solution of DPPH and a stock solution of sample $(1 \mathrm{mg} / \mathrm{ml})$ in methanol were prepared. Different concentrations of essential oil $(10-100 \mu \mathrm{g} / \mathrm{ml})$ were added to $1 \mathrm{ml}$ (0.5 mM DPPH) and final volume was made to $3 \mathrm{ml}$ with methanol. The mixture was shaken vigorously and kept standing at room temperature for $10 \mathrm{~min}$. Then the absorbance of the mixture was measured at $517 \mathrm{~nm}$ on spectrophotometer. The decrease in the absorbance indicates an increase in DPPH-radical scavenging activity. The percentage inhibition was calculated by the following equation.

$$
\text { DPPH radical scavenging }(\%)=\left[\frac{\mathrm{A}_{\mathrm{C}}-\mathrm{A}_{\mathrm{S}}}{\mathrm{A}_{\mathrm{C}}}\right] \times 100
$$

Where: $A_{c}$ is the absorbance of control, $A_{s}$ is absorbance of sample.

Table 1: Chemical profile of the essential oil from the flowers of Monarda citriodora.

\begin{tabular}{|c|c|c|c|}
\hline S. No & Compound & $\%$ Peak Area & $\begin{array}{c}\text { Methods of } \\
\text { identification }\end{array}$ \\
\hline 1 & a-Thujene & 0.2 & MS, RI \\
\hline 2 & a-Pinene & 1.0 & MS, RI \\
\hline 3 & $\beta$-Pinene & 0.9 & MS, RI \\
\hline 4 & a-Phellandrene & 0.1 & MS, RI \\
\hline 5 & a-Terpinene & 2.5 & MS, RI \\
\hline 6 & P-Cymene & 6.7 & MS, RI, \\
\hline 7 & Limonene & 0.2 & MS, RI \\
\hline 8 & Tricyclene & 4.5 & MS, RI, \\
\hline 9 & 4-Terpineol & 0.1 & MS, RI \\
\hline 10 & Methyl carvacrol & 0.4 & MS, RI \\
\hline 11 & Thymol & 76.7 & MS, RI, Std \\
\hline 12 & Carvacrol & 6.0 & MS, RI, Std \\
\hline \multirow[t]{2}{*}{13} & $\beta$-Caryophyllene & 0.1 & MS, RI \\
\hline & Total (\%) & 99.4 & \\
\hline \multicolumn{2}{|c|}{ Monoterpene hydrocarbons } & 16.1 & \\
\hline \multicolumn{2}{|c|}{ Oxygenated monoterpenes } & 83.2 & \\
\hline \multicolumn{2}{|c|}{ Sesquiterpene hydrocarbons } & 0.1 & \\
\hline \multicolumn{2}{|c|}{ Oxygenated sesquiterpenes } & nil & \\
\hline
\end{tabular}


The experiment was done in triplicate. $\mathrm{IC}_{50}$ value was calculated and indicated the concentration to scavenge $50 \%$ of DPPH free radicals.

The scavenging activity was performed by calculating the competing the essential oil and deoxyribose for hydroxyl radicals forming in Fenton reaction. Thiobarbituric acid reactive substances (TBARS) are formed when hydroxyl radicals get degraded by deoxyribose which can be spectroscopically measured at $532 \mathrm{~nm} .{ }^{12}$ The reaction mixture containing $25 \mathrm{mM}$ deoxyribose, $10 \mathrm{mM}$ ferric chloride, $100 \mathrm{mM}$ ascorbic acid, $2.8 \mathrm{mM} \mathrm{H}_{2} \mathrm{O}_{2}$ in $10 \mathrm{mM} \mathrm{KH}_{2} \mathrm{PO}_{4}(\mathrm{pH} 7.4)$ and various concentrations of essential oil of. Monarda citriodora. The reaction mixture was incubated at $37^{\circ} \mathrm{C}$ for $1 \mathrm{~h}$. Then $1 \mathrm{ml}$ each of $3 \%$ trichloroacetic acid and $1.6 \%$ thiobarbituric acid were supplied to the mixture followed by heating at $100^{\circ} \mathrm{C}$ for $20 \mathrm{~min}$. The TBARS was measured spectrophotometrically at $532 \mathrm{~nm}$. The results were expressed as percentage inhibition of deoxyribose oxidation and are determined by the following mathematical equation.

$$
\% \text { Inhibition }=[(\mathrm{A}-\mathrm{B}) / \mathrm{A}] \times 100
$$

Where: malonaldehyde generated in Fenton reaction is represented by "A" and malonaldehyde generated in presence of essential oil is represented by "B".

\section{Anticancer activity Human cell lines and culture}

Optimum density of seeded cell suspension was plated to each compartment of 96-well plates (Iwaki) and exposed to various essential oil concentrations ranging from $10-100 \mu \mathrm{g} / \mathrm{ml}$. Cells were cultured in a humidified atmosphere at $37^{\circ} \mathrm{C}$ in $5 \% \mathrm{CO}_{2}$. In the cultured RPMI- 1640 medium, standards which included 5-Fluoro uracil and Mitomycin-C (Sigma-Aldrich, Madrid, Spain) were used. The cells were incubated with sample for $48 \mathrm{hr}$ and fixed in cold ice TCA at $4^{\circ} \mathrm{C}$ for $1.5 \mathrm{~h}$. Plates were washed with distilled water followed by drying in open air in absence of light. Sulpharhodamine-B (SRB) solution (0.4\%) was added to each well of 96-well plates and allowed to stain at room temperature for $30 \mathrm{~min}$. The unbound SRB solution was removed by washing the plates quickly with $1 \%(\mathrm{v} / \mathrm{v})$ acetic acid. The bound SRB dye was solubilised by adding $100 \mu \mathrm{l}$ of $10 \mathrm{mM}$ unbuffered Tris base $(\mathrm{PH}=10.5)$ to each well and shaken for $5 \mathrm{~min}$ on shaker platform. The plates were read in a 96-well plate reader at $540 \mathrm{~nm}$.

\section{Cytotoxicity assay}

Sulpharhodamine-B assay was performed against four different human cancer cell lines which included Caco-2 (colon), HEP-2 (liver), A-549 (lung), and THP-1 (leukemia). An increase in growth of inhibition during $48 \mathrm{~h}$ incubation at all concentrations of 10, 20, 40, 60, 80 and $100 \mu \mathrm{g} / \mathrm{ml}$ of essential oil was seen. DMSO was set up separately as negative control to check cell death occurred by DMSO alone, which acted as solvent for dissolving samples homogeneously. Results were expressed as concentration of drug suppressing $50 \%$ cell growth $\left(\mathrm{IC}_{50}\right)$ and a significant cellular cytotoxic effect due to different essential oil concentrations was seen on different human cancer cell lines of varying tissue origin

\section{Statistical analysis}

Each separate experiment was executed in triplicate replicas, and mean values were calculated. The data were recorded as means \pm standard deviations. Analysis of variance for individual parameters was performed on the basis of mean values to find out the significance at $p<0.05$.

\section{RESULTS}

\section{Chemical composition of the essential oil}

The various chemical constituents identified in the essential oil of Monarda citriodora by making use of GC-MS technique are listed in Table 1, in order of their elution from an RTX-5 column. The GC-MS total ion chromatogram (TIC) of the essential oil is shown in Figure 1. A total of 20 constituents were identified from the essential oil comprising $91.9 \%$ of overall oil composition. The oil composition is dominated by the presence of monoterpene hydrocarbons and oxygenated sesquiterpene hydrocarbons accounting for $59.25 \%$ and $20.81 \%$ of the total oil composition respectively. Thymol, $\mathrm{p}$-cymene, and carvacrol were identified as the dominant compounds.

\section{Antibacterial activity}

The antimicrobial efficacies of Monarda citriodora essential oil were evaluated against a set of seven bacterial strains including both Gram +ve and Gram -ve strains and two fungal strains. Potency of essential oil against microbes was assessed qualitatively and quantitatively by the presence or absence of zone diameters $\left(\mathrm{ZD}_{\mathrm{S}}\right)$, inhibition zones, and respective MIC values. The results demonstrated in Table 2 represent that this essential oil displayed a variable degree of antimicrobial activity. Staphylococcus epidermidis MTCC-435, P. aeruginosa and S. typhi were the most sensitive bacterial strains to the essential oil. B. subtillis and K. pneumonia were moderately sensitive while as $S$. dyssentriae and S. aureus were least sensitive towards essential oil of Monarda citriodora. In case of antifungal activity essential oil was appreciably potent towards both the fungal strains. Antimicrobial efficacies of essential oil were further compared with that of standard antibiotics by disc diffusion method.

\section{Antioxidant activity \\ DPPH free radical scavenging activity}

Figure 2 shows the scavenging effect of essential oil of Monarda citriodora on the DPPH radical. DPPH is a stable radical that loses its purple colour when it undergoes reduction by accepting an electron from an antioxidant molecule. Ascorbic acid was considered as reference compound. A comparable and dose-reliant scavenging effectively was shown by the oil to that of reference standard (ascorbic acid) at higher concentrations. The $\mathrm{IC}_{50}$ value of the essential oil was found to be $19.3 \mu \mathrm{g} / \mathrm{ml}$.

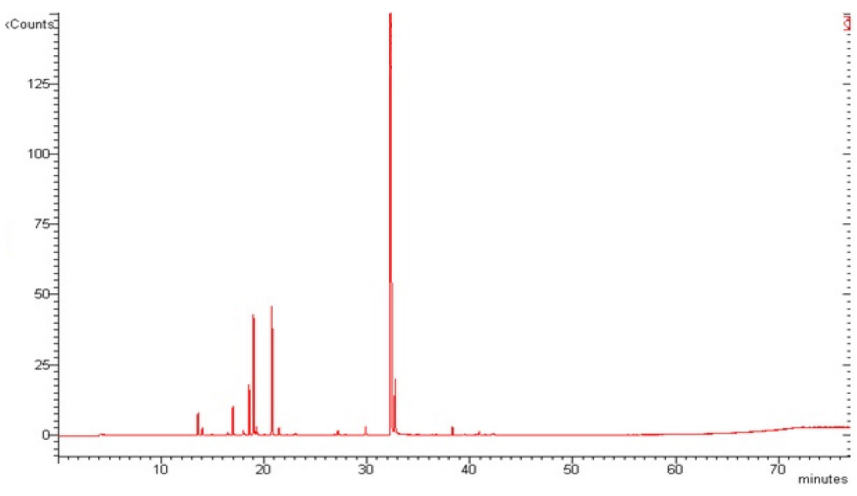

Figure 1: GC-MS Total Ion Chromatogram (TIC) of the flower essential oil of Monarda citriodora. 
Table 2: Antimicrobial activity of the essential oil of Monarda citriodora (MIC and MBC values).

\begin{tabular}{|c|c|c|c|c|c|c|c|c|c|}
\hline \multirow[t]{2}{*}{ S.NO } & \multirow[t]{2}{*}{ Micro-organism } & \multicolumn{2}{|c|}{ Essential oil $(\mu \mathrm{g} / \mathrm{ml})$} & \multicolumn{2}{|c|}{ Ampicillin } & \multicolumn{2}{|c|}{ Vancomycin } & \multicolumn{2}{|c|}{ Fluconazole } \\
\hline & & MIC & MBC & MIC & MBC & MIC & MBC & MIC & $\mathrm{MBC}$ \\
\hline 1 & B. subtillis & 64 & $>64$ & 0.5 & $>1$ & 0.5 & 1 & NT & NT \\
\hline 2 & S. epidermidis & 16 & $>16$ & 2 & 4 & 1 & 2 & NT & NT \\
\hline 3 & P. aeruginosa & 16 & 32 & 2 & 4 & 2 & 4 & NT & NT \\
\hline 4 & S. aureus & 8 & 16 & 0.5 & 1 & 2 & 4 & NT & NT \\
\hline 5 & S. typhi & 16 & $>32$ & 4 & $>4$ & 0.5 & $>0.5$ & NT & NT \\
\hline 6 & S. dyssenteriae & 16 & $>32$ & 4 & 8 & 1 & 2 & NT & NT \\
\hline 7 & K. pneumonia & 32 & $>64$ & 1 & $>2$ & 0.5 & 1 & NT & NT \\
\hline 8 & P. chrysogenum & 32 & 64 & NT & NT & NT & NT & 0.5 & 1 \\
\hline 9 & niger & 32 & $>64$ & NT & NT & NT & NT & 0.5 & $>1$ \\
\hline
\end{tabular}

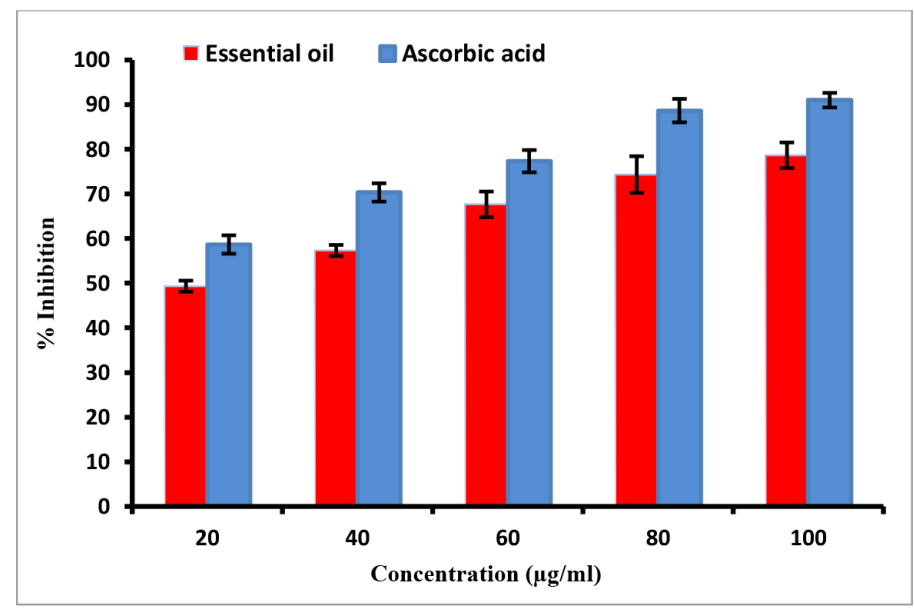

Figure 2: Antioxidant activity of the essential oil of Monarda citriodora as evaluated by DPPH radical scavenging assay. All the values are mean \pm SEM $(n=3)$.

\section{Hydroxyl radical scavenging activity}

In the present study (Figure 3), hydroxyl radical scavenging potential of essential oil was estimated by generating hydroxyl radicals using ascorbic acid-iron- $\mathrm{H}_{2} \mathrm{O}_{2}$ (Fenton reaction ) and their subsequent scavenging in presence of essential oil samples. The antioxidant efficacy of essential oil was found to be comparable to the reference standard (ascorbic acid). This ability of the essential oil to quench hydroxyl radicals could be coordinated to the prevention of lipid peroxidation, carcinogenisis and mutagenesis. The $\mathrm{IC}_{50}$ value was found to be $39.2 \mu \mathrm{g} / \mathrm{ml}$. subsequent scavenging in presence of essential oil samples. The antioxidant efficacy of oil was found to be comparable against reference standard (ascorbic acid). This ability of the essential oil to quench hydroxyl radicals could be coordinated to the prevention of lipid peroxidation, carcinogenisis and mutagenesis. The $\mathrm{IC}_{50}$ values of the essential oil was found to be $39.2 \mu \mathrm{g} / \mathrm{ml}$. oil to quench hydroxyl radicals can be related to the prevention of lipid peroxidation, carcinogenisis and mutagenesis. The $\mathrm{IC}_{50}$ value was determined to be $39.2 \mu \mathrm{g} / \mathrm{ml}$. subsequent scavenging in presence of essential oil samples. The antioxidant activity of the essential oil was found to be comparable to the reference standard (ascorbic acid). The $\mathrm{IC}_{50}$ values of the essential oil was found to be $39.2 \mu \mathrm{g} / \mathrm{ml}$.

\section{Cytotoxic activity}

The cytotoxic potential of the Monarda citriodora essential oil was studied using cultured Caco-2, Hep-2, A-549, and THP-1 cancer cell lines by

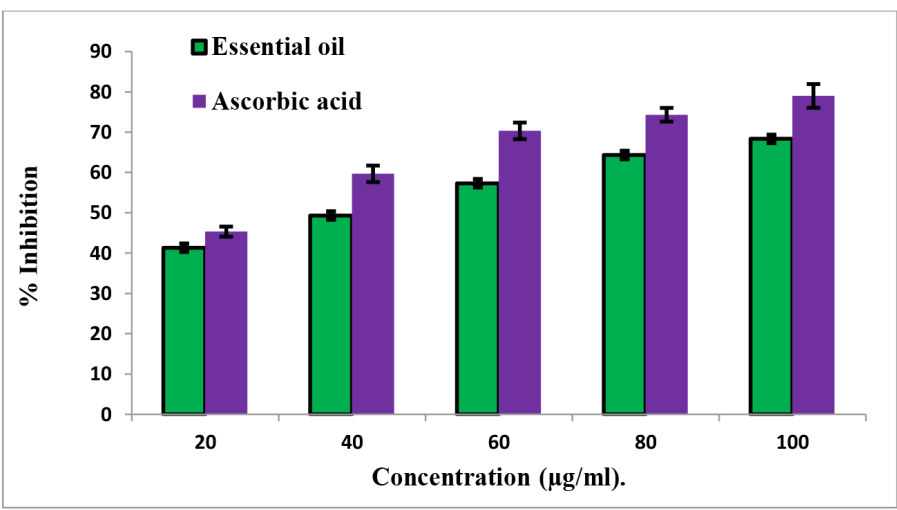

Figure 3: Antioxidant activity of the essential oil of Monarda citriodora as evaluated by hydroxyl radical scavenging assay. All the values are mean \pm $\operatorname{SEM}(n=3)$.

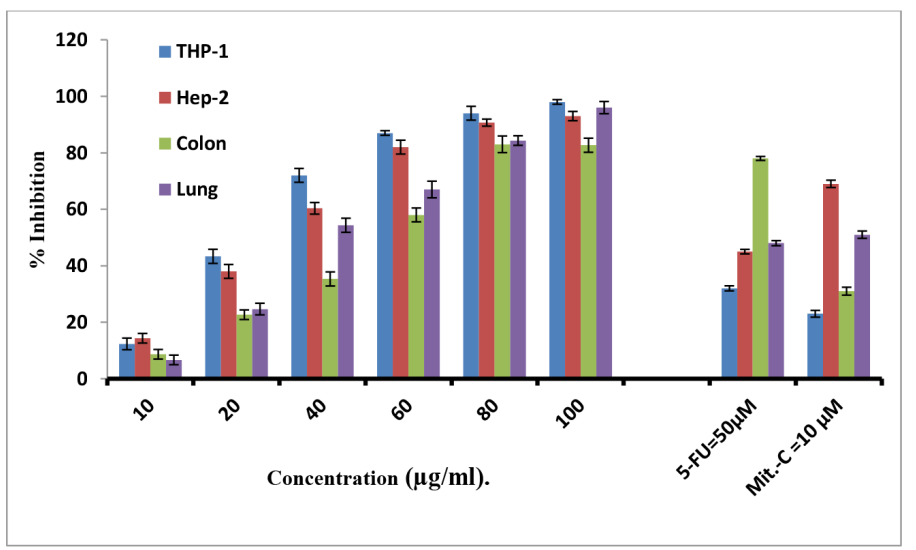

Figure 4: Cytotoxic activity of essential oil against human cancer cell lines. All the values are mean $\pm \operatorname{SEM}(n=3)$.

sulphorhodamine-B assay. The cell lines were subjected to increasing dose of the essential oil ranging from $10-100 \mu \mathrm{g} / \mathrm{ml}$ for $48 \mathrm{hr}$ which reduced the viability of these cell lines. Figure 4 shows that the oil was significantly active against all the four tested cell lines. The percentage of the dead cells in case of THP-1 (leukemia), Hep-2 (liver), Caco-2 (colon) and A-549 (lung) was found to be $99 \%, 93 \%, 85 \%$ and $97 \%$ respectively for the essential oil concentration of $100 \mu \mathrm{g} / \mathrm{ml}$. The essential oil exhibited a dose-dependent inhibitory effect on all cell lines tested in the $10-100 \mu \mathrm{g} / \mathrm{ml}$ 
Wani and Yadav.: Chemical Composition and Antimicrobial Activity of Monarda citriodora

dilution range (Figure 2). The $\mathrm{IC}_{50}$ values of the essential oil were found to be $24.2 \mu \mathrm{g} / \mathrm{ml}$ (THP-1), $55.5 \mu \mathrm{g} / \mathrm{ml}$ (A-549), $31 \mu \mathrm{g} / \mathrm{ml}$ (HEP-2) and $37.5 \mu \mathrm{g} / \mathrm{ml}$ (Caco-2).

\section{DISCUSSION}

Medicinal and aromatic plants are important and valuable gifts of nature. They are botanical raw materials and also named as herbal drugs. Medicinal and aromatic plants are principally incorporated in aromatic, therapeutic and culinary purposes as modules of medicinal products, healthy foods, cosmetics and natural products. ${ }^{26}$ They also act as starting material in value-added processed natural ingredients including dry and liquid extracts, essential oils and oleoresins.

Reactive oxygen species (ROS) and reactive nitrogen species (RNS) production is continuously balanced by natural antioxidant defence system, but with aging this defence system becomes weak and as such some other alternative has to be there which should be strong enough to take care of the in significant natural antioxidant potential. ${ }^{27}$ Consumption diet rich in antioxidant content is always a vital strategy in regulating the oxidation of desired vulnerable substrates present in cells and hence results in prevention of a number of disorders relevant to this change. Flavonoids, phenolic acids, tannins and essential oils have been well documented to possess antioxidant activity and thus represent an important choice to be used in case of resulting circumstances. Hydroxyl radical is known for its extremely reactive nature in biological systems with capacity of causing fragmentation of genetic material hence contributes to carcinogenisis, mutagenesis and cytotoxicity. In order to avoid a major toll to DNA damage there should be some systems either in built or transported from outside at the time of urgency which are capable of quenching these super reactive species. From literature survey, mono and sesqui terpenes which form the bulk of essential oils are gifted with such properties. This ability of the essential oil to quench hydroxyl radicals can be related to the prevention of lipid peroxidation, carcinogenisis and mutagenesis. ${ }^{28}$ The essential oil obtained from under investigation plant showed high variety of chemical composition responsible for its phenomenal antioxidant potential.

Different nature of interactions between receptors and essential oil constituents, permeability and diffusion of various hydrophobic agents across the cell membrane etc. may influence the extent of the microbial susceptibility. Herein, we found that Monarda citriodora essential oil possesses significant antimicrobial activity which may be attributed to its chemical constituents identified.

Moreover, it has been well documented that essential oils obtained from medicinal plants show efficient antiproliferative activities against a broad spectrum of human cancer cell lines. ${ }^{29}$ Medicinal plants and their derived phytochemicals have been a backbone for current day pharmacy and several chemotherapeutic agents from plant source have been already approved and some are in clinical trials. ${ }^{30}$ In the present research, we investigated the antiproliferative activity of the Monarda citriodora essential oil against Caco-2 (colon), HEP-2 (liver), A-549 (lung), and THP-1 (leukemia) cells. The results showed efficient inhibitory effects for the Monarda citriodora essential oil against these selected target cell lines.

\section{CONCLUSION}

The current study revealed potential antimicrobial, antiproliferative and antioxidant activities of Monarda citriodora essential oil can be of immense importance to devise further experiments for standardizing the activity profile of this essential oil so that it can find potential applications in pharmaceutical industries for curbing microbe born infectious diseases.

\section{CONFLICT OF INTEREST}

The authors declare that there is no conflict of interest to indicate.

\section{ABBREVIATIONS}

ROS: Reactive Oxygen Species; RNS: Reactive Nitrogen Species; DPPH: 2,2-dipheny-1-picryl hydrazyl); GC-FID: Gas Chromatography Flame Ionization Detection; GC-MS: Gas Chromatography-Mass Spectrometry.

\section{REFERENCES}

1. Gundidza M.. Antimicrobial activity of essential oil from Schinus molle Linn. Cent Afr J Med. 1993;39(11):231-4. PMID 8055554.

2. Kirkland KB, Briggs JP, Trivette SL, Wilkinson WE, Sexton DJ. The impact of surgical-site infections in the 1990s: attributable mortality, excess length of hospitalization, and extra costs. Infect Control Hosp Epidemiol. 1999;20(11):725-30. doi: 10.1086/501572, PMID 10580621

3. Mastoraki A, Kriaras I, Douka E, Mastoraki S, Stravopodis G, Geroulanos S. Methicillin-resistant Staphylococcus aureus preventing strategy in cardiac surgery. Interact Cardiovasc Thorac Surg. 2008;7(3):452-6. doi: 10.1510/ icvts.2008.176156, PMID 18346978

4. Geha DJ, Uhl JR, Gustaferro CA, Persing DH.. Multiplex PCR for identification of methicillin-resistant staphylococci in the clinical laboratory. J Clin Microbiol. 1994;32(7):1768-72. doi: 10.1128/jcm.32.7.1768-1772.1994, PMID 7929772

5. Edries AE. Pharmaceutical and therapeutic potentials of essential oils and their individual volatile constituents: a review. Phytother Res. 2007;21(4):308-23. doi: 10.1002/ptr.2072, PMID 17199238.

6. Hammer KA, Carson CF, Riley TV. Antimicrobial activity of essential oils and other plant extracts. J Appl Microbiol. 1999;86(6):985-90. doi: 10.1046/j.13652672.1999.00780.x, PMID 10438227.

7. Buchbauer G, Jirovetz L. Aromatherapy-use of fragrances and essential oils as medicaments. Flavour Fragr J. 1994;9(5):217-22. doi: 10.1002/ffj.2730090503.

8. Bruneton J. Pharmacognosy, Pphytochemistry, Mmedicinal Pplants,. $2^{\text {nd }}$ edition,. London: Intercept Ltd. London.; 1999:539-40.

9. Burt S. Essential oils: their antibacterial properties and potential applications in foods - a review. Int J Food Microbiol. 2004;94(3):223-53. doi: 10.1016/j.ijfoodmicro.2004.03.022, PMID 15246235.

10. Sylvestre M, Pichette A, Longtin A, Nagau F, Legault J.. Essential oil analysis and anticancer activity of leaf essential oil of Croton flavens L. from Guadeloupe. J Ethnopharmacol. 2006;103(1):99-102. doi: 10.1016/j.jep.2005.07.011, PMID 16168586.

11. Kordali S, Kotan R, Mavi A, Cakir A, Ala A, Yildirim A. Determination of the chemical composition and antioxidant activity of the essential oil of Artemisia dracunculus and of the antifungal and antibacterial activities of Turkish Artemisia absinthium, A. dracunculus, Artemisia santonicum, and Artemisia spicigera essential oils. J Agric Food Chem. 2005;53(24):9452-8. doi: 10.1021/jf0516538, PMID 16302761.

12. Bozin B, Mimica -Dukic N, Simin N, Anackov G. Characterization of the Volatile Composition of Essential Oils of Some Lamiaceae Spices and the Antimicrobial and Antioxidant Activities of the Entire Oils. J Agric Food Chem. 2006;54(5): 1822-8. doi: 10.1021/jf051922u.

13. Nguefack J, Budde BB, Jakobsen M. Five essential oils from aromatic plants of Cameroon: their antibacterial activity and ability to permeabilize the cytoplasmic membrane of Listeria innocua examined by flow cytometry. Lett Appl Microbiol. 2004;39(5):395-400. doi: 10.1111/j.1472-765X.2004.01587.x, PMID 15482428.

14. Schmidt E, Jirovetz L, Buchbauer G, Denkova Z, Stoyanova A, Murgov I., Geissler M. Antimicrobial Testings and Gas Chromatographic Analyses of Aroma Chemicals. J Essent Oil- Bear Plants. 2005;8(1):99-106. doi: 10.1080/09 72060X.2005.10643427.

15. Dar MY, Shah WA, Rather MA, Qurishi Y, Hamid A, Qurishi MA. Chemical composition, in vitro cytotoxic and antioxidant activities of the essential oil and major constituents of Cymbopogon jawarancusa (Kashmir). Food Chem. 2011;129(4):1606-11. doi: 10.1016/j.foodchem.2011.06.016.

16. Yousuf Dar MY, Shah WA, Mubashir S, Rather MA. Chromatographic analysis, anti-proliferative and radical scavenging activity of Pinus wallichina essential oil growing in high altitude areas of Kashmir, India. Phytomedicine. 2012;19(13):1228-33. doi: 10.1016/j.phymed.2012.07.015, PMID 22939260.

17. Rather MA, Dar BA, Dar MY, Wani BA, Shah WA, Bhat BA, Ganai BA, Bhat KA, Anand R, Qurishi MA. Chemical composition, antioxidant and antibacterial activities of the leaf essential oil of Juglans regia $L$. and its constituents. Phytomedicine. 2012;19(13):1185-90. doi: 10.1016/j.phymed.2012.07.018, PMID 22951389.

18. Rashid S, Rather MA, Shah WA, Bhat BA. Chemical composition, antimicrobial, cytotoxic and antioxidant activities of the essential oil of Artemisia indica Willd Food Chem. 2013;138(1):693-700. doi: 10.1016/j.foodchem.2012.10.102, PMID 
23265542

19. Manosroi J, Dhumtanom P, Manosroi A. Anti-proliferative activity of essential oil extracted from Thai medicinal plants on KB and P388 cell lines. Cancer ILet.t. 2006;235(1):114-20. doi: 10.1016/j.canlet.2005.04.021, PMID 15979235.

20. Crowell PL. Prevention and therapy of cancer by dietary monoterpenes J Nutri. 1999;129(3):775S-778S. doi: 10.1093/jn/129.3.775S, PMID 10082788.

21. Collins JE, Bishop CD, Deans SG, Svoboda KP. Composition of the essential oil from the leaves and flowers of Mmonarda citriodora var. citriodora grown in the United Kingdom. J Essent Oil Res. 1994;6(1):27-9. doi: 10.1080/10412905.1994.9698320.

22. Jennings $W$, Shibamoto T. Qualitative analysis of flavour and fragrance volatile by glass capillary gas chromatography,. New York: Academic press, Inc. New York.; 1980

23. Adams P. Identification of essential oil components by Gas Chromatography/ Mass Spectrometry, Allured Publishing Corp., Carol Stream, Illinois, USA. 2007.

24. Norrel SA, Messley KE. Microbiology Laboratory Mmanual Pprinciples and Aapplications. Prentice Hall, Englewood Cliffs: Prentice Hall, 1997; . pp. 85-90.

25. Barry A.. The Aantimicrobic Ssusceptibility Ttest:. Philadelphia: Principles and
Practices., Lea and \& Febiger, Philadelphia.; 1976.

26. Lubbe $A$, Verpoorte $R$. Cultivation of medicinal and aromatic plants for specialty industrial materials. Ind Crops Prod. 2011;34(1):785-801. doi: 10.1016/j. indcrop.2011.01.019.

27. Pan YM, Wang K, Huang SQ, Wang HS, Mu X M, He CH, Ji X, Zhang J, Huang F Antioxidant activity of microwave-assisted extract of longan (Dimocarpus Llongan Lour.) peel. Food Chem. 2008;106(3):1264-70. doi: 10.1016/j.foodchem.2007.07.033

28. Edris AE. Pharmaceutical and therapeutic potentials of essential oils and their individual volatile constituents: a review. Phytotherapy Research. 2007;21(4):308 23. doi: 10.1002/ptr.2072, PMID 17199238.

29. Bhalla Y, Gupta VK, Jaitak V.. Anticancer activity of essential oils: a review. J Sci Food Agric. 2013;93(15):3643-53. doi: 10.1002/jsfa.6267, PMID 23765679

30. Khursheed A, Jain V, Rasool A, Rather MA, Malik NA, Shalla AH. Molecular scaffolds from Mother Nature as possible lead compounds in drug design and discovery against coronaviruses: A landscape analysis of published literature and molecular docking studies. Microb Pathog. 2021:104933:157:104933. doi: 10.1016/j.micpath.2021.104933.

Article History: Submission Date : 14-05-2021; Revised Date : 29-05-2021; Acceptance Date : 28-06-2021.

Cite this article: Wani AR, Yadav K. Chemical Characterization, Antimicrobial, Antiproliferative and Antioxidant Activities of the Essential Oil of Monarda citriodora growing in Kashmir. Int. J. Pharm. Investigation. 2021;11(2):170-5. 